\title{
Experimental study on recycled concrete containing recycled fibers and organic fibers
}

\author{
ZHANG Yong ${ }^{1, a}$, LIU Qiong ${ }^{2, b,{ }^{*}}$ \\ ${ }^{1}$ Qingdao Vocational and Technical College of Hotel Management, 599 Jiushuidong Road, \\ Qingdao, 266100, Shangdong Province, China \\ ${ }^{2}$ Faculty of Civil Engineering and Mechanics, Jiangsu University, 301 Xuefu Road, Zhenjiang, \\ 212013, Jiangsu Province, China \\ aeroszhang@126.com, bliuqiong@ujs.edu.cn
}

\begin{abstract}
Keywords: Construction and demolished waste; Recycled aggregates; Recycled concrete; Fibers; Abstract. Recycled concrete is an environmental green material for recycling construction and demolished wastes. Numerous studies performed on recycled concrete indicated that it had poor characteristics of workability, strength and durability attribute to the inferior mechanical properties of recycled aggregates. A wide range of investigations had been carried out to improve the mechanical properties of recycled concrete. For better manifesting green concepts, waste glass-fiber composite tablets, recycled PET fibers and organic sisal fibers were used in this study to enhance the mechanical properties of recycled concrete. The experimental results show that the smooth surface of composite tablets may be weak points to degrade its compressive strength. PET fibers and sisal fibers can improve the ductility of recycled concrete obviously.
\end{abstract}

\section{Introduction}

Construction and demolished wastes (C\&D wastes) generally consist of materials used in civil construction. As increasing concrete structures are approaching the end of their expected lifespan, finding economical and environment-friendly strategies to manage the disposal of C\&D wastes is essential towards the sustainable environment. A promising practice to meet this goal is to utilize C\&D wastes to generate recycled materials and then use them again to produce "green" construction materials.

Recycled concrete (RC), an environmental green construction material, uses processed or rather crushed waste concrete as recycled aggregates. Numerous studies performed on RC indicated that it had poor characteristics of workability, strength and durability due to the degraded mechanical properties of recycled aggregates [1-4].

A wide range of investigations had been performed to improve the mechanical properties of RC. The addition of steel fibers can boost its strength and delay its damages occurrence [5]. Silicon fume can also enhance the compressive strength of RC [6]. Surface pre-coating with thin cement paste for recycled aggregates resulted in better workability and mechanical properties of $\mathrm{RC}$ [7]. $\mathrm{CO}_{2}$ curing was proposed in recent years to pre-treat recycled aggregates, which leaded to a denser structure of the recycled aggregates and, as a result, a higher strength of $\mathrm{RC}$ [8]. Tam proposed a special treatment method, two stage mixing approach, to improve the mechanical properties of RC [9].

Using recycled fibers or organic fibers to improve the mechanical properties of RC is a great way to manifest environmental protection wider and deeper. Glass-fiber composites, owning an outstanding durability, are widely used in construction and auto industries. However, a good durability also means barely degrading in natural environment. So that, mixing waste glass-fiber composite plates and car bumpers into concrete may be a promising way to recycle them and incidentally improve RC's mechanical properties.

PET bottles used as drinks' containers can be seen everywhere and thousands tons of waste PET bottles are generated every year. They have been recycled to produce fibers, which can be used in concrete to prevent shrinkage cracks [10]. 
Organic fibers are regarded as real green materials due to the fact that they can degrade completely. Silva's research [11] showed that sisal fibers can work well in cement composites and improve the bending strength of flat concrete sheets by $260 \%$.

Waste glass-fiber composites, recycled PET fibers and sisal fibers are great options as additives to enhance the mechanical properties and ductility of RC. In this paper, compressive strength and Young's modulus of RC containing various additives were tested to determine their quantitative influence on the mechanical properties of RC. Their failure modes were also discussed to understand the ductility.

\section{Experimental details}

Materials. Ordinary type I Portland cement in the light of ASTM C31, medium river sand with a fineness modulus of 2.56, natural and recycled coarse aggregates with a size ranging from $5 \mathrm{~mm}$ to $15 \mathrm{~mm}$ were prepared to mix concrete. In addition, natural aggregates and recycled aggregates were treated to be under saturated surface dry condition before mixing by soaking them in water for 24 hours and wipe dry their surfaces.

Glass-fiber composite plates with a thickness of $1 \mathrm{~mm}$, collected from a factory as wastes, were cut into a size of $5 \mathrm{~mm}$ width and $20 \mathrm{~mm}$ length, as shown in Fig. 1-a.

Recycled PET fibers have a length of $12 \mathrm{~mm}$ and a diameter of $35 \mu \mathrm{m}$, as shown in Fig. 1-b. They were bought from a PET bottle recycling factory, in which PET bottles (water or cola bottles) were melted and processed to become fibers.

A sisal twine was cut to $20 \mathrm{~mm}$ long as shown in Fig. 1-c. After soaked in water for half an hour, the sisal fibers can be dispersed as shown in Fig. 1-d. 


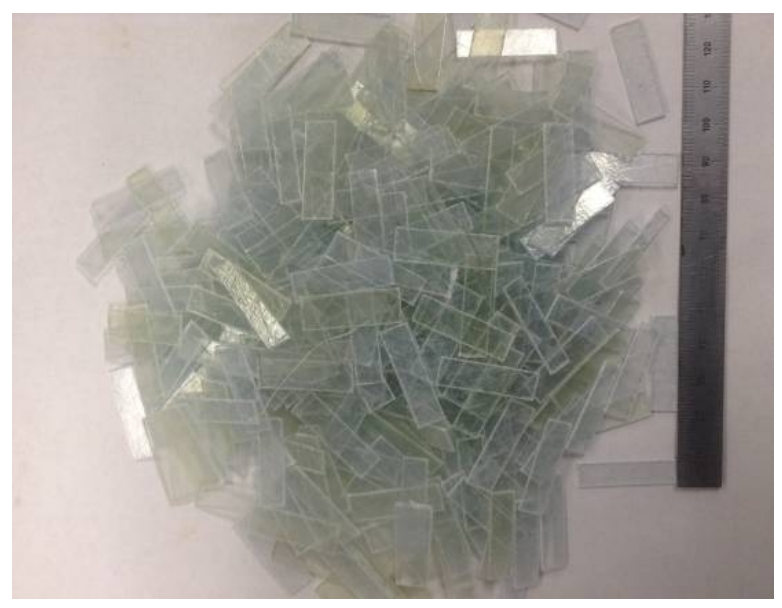

a) Composite plate tablets

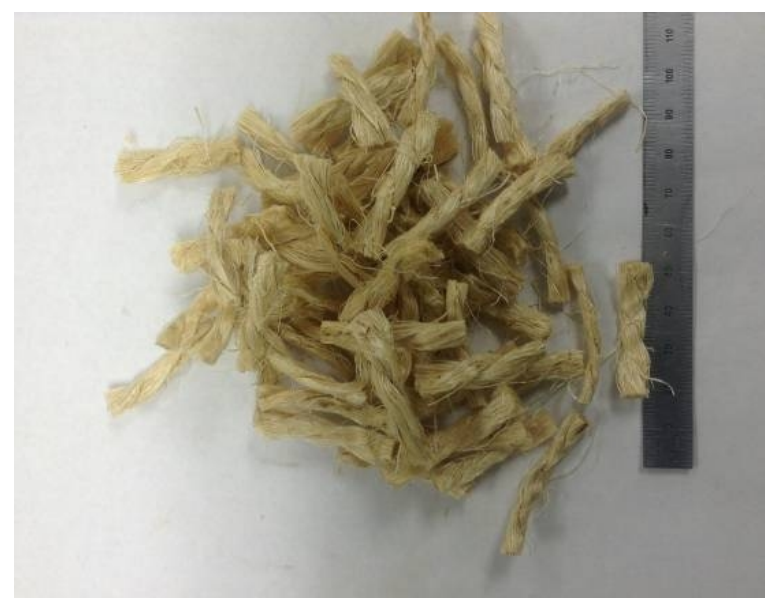

c) Sisal twist

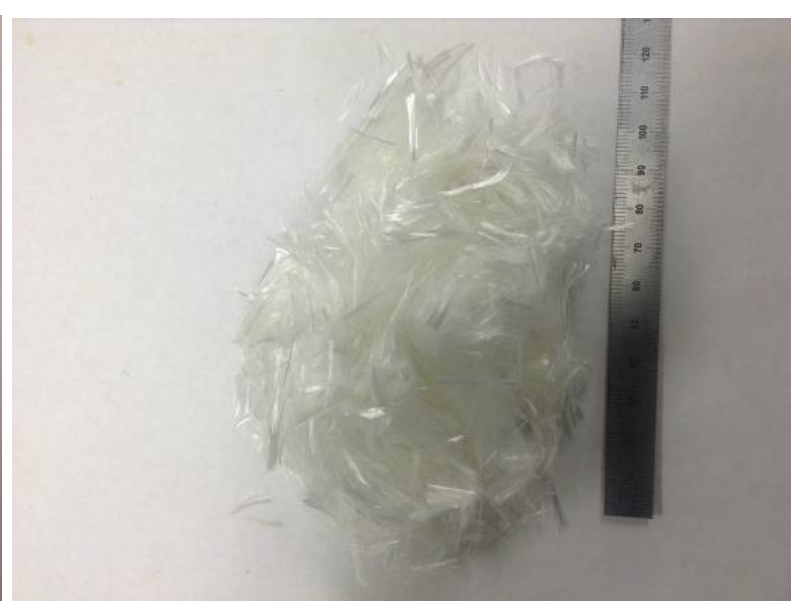

b) PET fibers

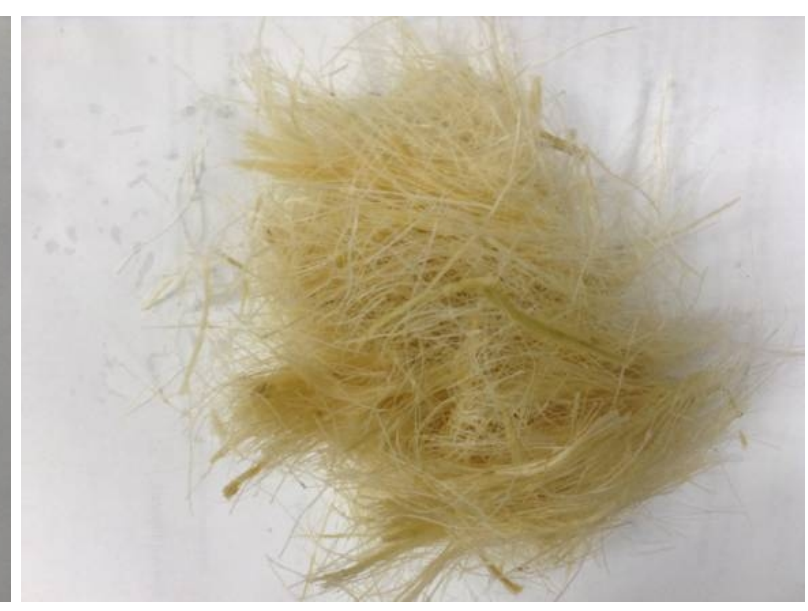

d) Sisal fibers soaked by water

Fig. 1 Three kinds of addition materials

Mix proportions. The mix proportions are shown in Table 1, in which, 'NC' represents normal concrete, 'RC' recycled concrete, 'RC-C-2\%' the RC containing composite tablets (volume content $2 \%$ ), 'RC-P- $0.5 \%$ ' the RC containing PET fibers (volume content $0.5 \%$ ), 'RC-S-0.5\%' the RC containing sisal fibers (volume content $0.5 \%$ ).

From the mix proportions of $\mathrm{NC}$ and $\mathrm{RC}$, a difference can be easily seen. The apparent density of natural aggregates used in this experiment had been tested to be $2670 \mathrm{~kg} / \mathrm{m}^{3}$ and that of recycled aggregates $2445 \mathrm{~kg} / \mathrm{m}^{3}$. It was attempted to have the same coarse aggregates volume content. Therefore, after calculating, the coarse aggregates (in weight) in NC and RC were $1275 \mathrm{~g}$ and $1168 \mathrm{~g}$ respectively.

For RC containing composite tablets, three different volume contents, $2 \%, 1 \%$ and $0.5 \%$, were considered to find out their influence on the mechanical properties of RC. While, for PET fibers and sisal fibers, the volume content of fibers were $0.5 \%, 0.25 \%$ and $0.125 \%$. When the volume content of PET fibers or sisal fibers was higher than $0.5 \%$, it was hard to mix them into concrete evenly. It is because the PET fibers and sisal fibers were fine and tend to gather together during mixing. On the contrary, $0.5 \%$ volume content was quite small for composite tablets. Therefore, the volume contents of composite tablets were chosen to be $2 \%, 1 \%$ and $0.5 \%$. 
Table. 1 Mix proportions

\begin{tabular}{|l|c|c|c|c|c|c|c|c|}
\hline & $\begin{array}{c}\text { Cement } \\
(\mathrm{g})\end{array}$ & $\begin{array}{c}\text { Natural } \\
\text { aggregates } \\
(\mathrm{g})\end{array}$ & $\begin{array}{c}\text { Recycled } \\
\text { aggregates } \\
(\mathrm{g})\end{array}$ & $\begin{array}{c}\text { Sand } \\
(\mathrm{g})\end{array}$ & $\begin{array}{c}\text { Water } \\
(\mathrm{g})\end{array}$ & $\begin{array}{c}\text { Composite } \\
\text { tablets } \\
(\mathrm{g})\end{array}$ & $\begin{array}{c}\text { PET } \\
\text { fibers } \\
(\mathrm{g})\end{array}$ & $\begin{array}{c}\text { Sisal } \\
\text { fibers } \\
(\mathrm{g})\end{array}$ \\
\hline $\mathrm{NC}$ & 340 & 1275 & 0 & 600 & 185 & 0 & 0 & 0 \\
\hline RC & 340 & 0 & 1168 & 600 & 185 & 0 & 0 & 0 \\
\hline RC-C-2\% & 340 & 0 & 1168 & 600 & 185 & 40 & 0 & 0 \\
\hline RC-C-1\% & 340 & 0 & 1168 & 600 & 185 & 20 & 0 & 0 \\
\hline RC-C-0.5\% & 340 & 0 & 1168 & 600 & 185 & 10 & 0 & 0 \\
\hline RC-P-0.5\% & 340 & 0 & 1168 & 600 & 185 & 0 & 7 & 0 \\
\hline RC-P-0.25\% & 340 & 0 & 1168 & 600 & 185 & 0 & 3.5 & 0 \\
\hline $\begin{array}{l}\text { RC-P-0.125 } \\
\%\end{array}$ & 340 & 0 & 1168 & 600 & 185 & 0 & 1.75 & 0 \\
\hline RC-S-0.5\% & 340 & 0 & 1168 & 600 & 185 & 0 & 0 & 7 \\
\hline RC-S-0.25\% & 340 & 0 & 1168 & 600 & 185 & 0 & 0 & 3.5 \\
\hline $\begin{array}{l}\text { RC-S-0.125 } \\
\%\end{array}$ & 340 & 0 & 1168 & 600 & 185 & 0 & 0 & 1.75 \\
\hline
\end{tabular}

Test method. Cylinder specimens with a height of 8 inches and a diameter of 4 inches were used to obtain the compressive strength, Young's modulus and Poisson ratio. All the concrete specimens were prepared in accordance with the requirements of ASTM C31. After being demolded, the specimens were stored in a standard curing room having a temperature of $23{ }^{\circ} \mathrm{C}$ and a relative humidity of $95 \%$ for 28 days till testing.

The ultimate strengths of specimens were determined by following ASTM C39. This involved applying a compressive axial load at a rate of $20 \mathrm{psi} / \mathrm{s}$ continuously until failure occurred. The specimens were tested by using the standard static loading method to determine their Young's modulus specified in ASTM C469. The test procedure started from applying the load at a constant rate within the range $35 \pm 5 \mathrm{psi} / \mathrm{s}$ until it reaches $40 \%$ of the ultimate load and returning the load to zero at the same rate. The first two loading circles were primarily used to seat the strain measuring equipment and should not be recorded.

\section{Results and discussions}

Failure appearances. All the samples tended to fail along an inclined section area, but not the 'cup' and 'core' pattern. It was because the rubber plates in the loading caps let the concrete expand freely on both ends of the samples. Without the friction between the end surfaces of samples and the surfaces of the loading head of the equipment, the 'cup' and 'core' pattern would not be generated during loading. As a result, inclined failure sections were observed in all the samples as shown in Fig. 2

The composite tablets were found to scatter in concrete in Fig. 2a. On the failure sections, a bunch of composite tablets can be found and the failure process showed more brittleness. It may result from that the tablets is not long enough to prevent crack propagating, moreover, the smooth surfaces of tablets act as weak points in RC.

Obvious ductile failure processes were observed for RC specimens containing PET fibers and sisal fibers. Although clear inclined failure sections had been observed, the sample kept as a whole because 
of the fibers. The broken samples shown in Fig. 2b and Fig. 2c were separated by tearing up the connecting fibers.

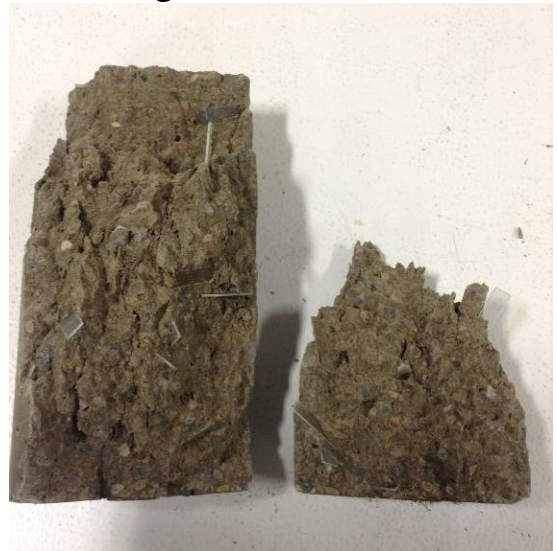

a) Composite plate tablets

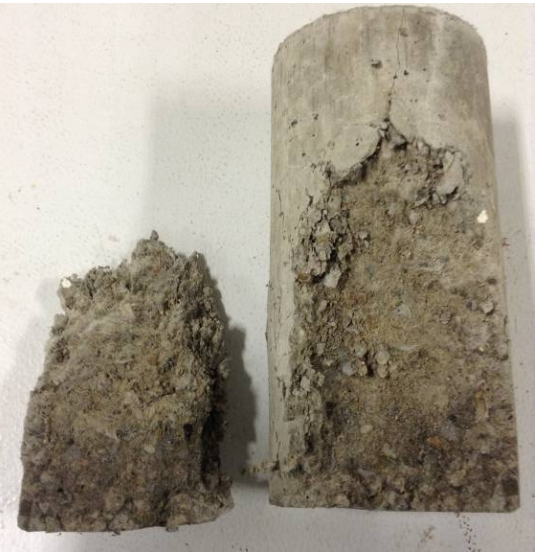

b) PET fibers

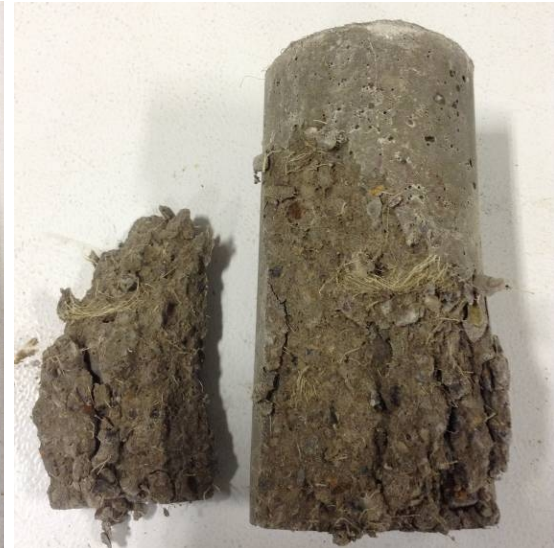

c) Sisal fibers

Fig. 2Failure appearances of RC containing different additives

Compressive strength. The compressive strengths shown in Fig. 3were obtained with the average of three samples.

According to Fig. 3a, NC and RC have compressive strengths of $37.3 \mathrm{MPa}$ and $31.1 \mathrm{MPa}$ respectively. A $16.6 \%$ decrease can be seen when the natural coarse aggregates is replaced by recycled ones. The difference between NC and RC should be only result from the strength of coarse aggregates. Because NC and RC have the same volume quantities of mortar paste and coarse aggregates, and it should also be believed that the mortar paste in NC and RC has the same strength according to their mix proportions.

From Fig. 3a, the strength of RC containing composite tablets is lower than that of pure RC, without containing any tablets or fibers. Among them, RC-C-1\% has a lowest strength of $27.4 \mathrm{MPa}$, which is $88 \%$ as to pure RC. It may be summarized that the composite tablets have a negative influence on the compressive strength of RC because of its smooth surfaces being able to generate weak points in RC.

The compressive strength of RC containing PET fibers is shown in Fig. 4-b. An overall downtrend can be found as increasing the content of PET fibers. The additive of PET fibers also leads to a degradation for the compressive strength. However, ductile failure processes can be observed from the tests. And also, the more PET fibers are added, the more ductile they are.

From Fig. 4-c, an overall downtrend can be also found while increasing the ratio of sisal fibers. Even, the strength of RC-C- $0.5 \%$ is only $70 \%$ of pure RC. During mixing sisal fibers into concrete, a great number of small air bubbles were generated, which may be the reason of such a low strength.

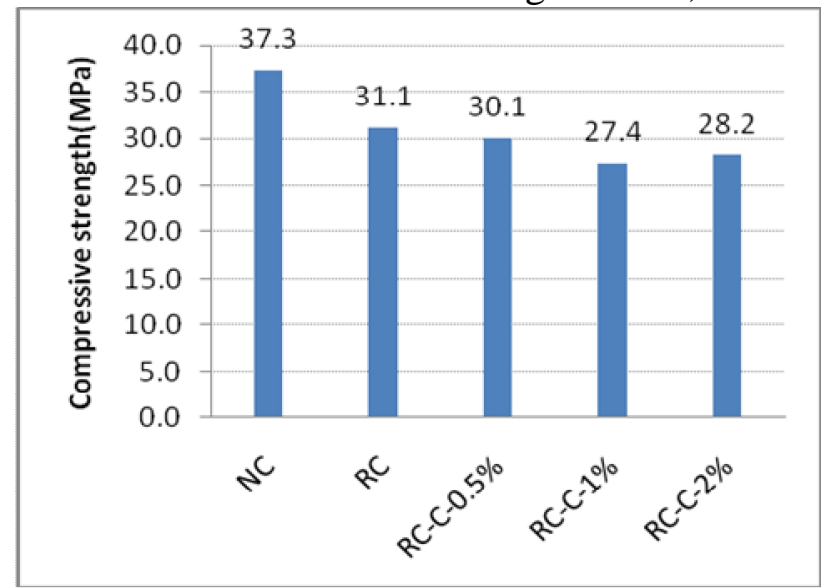

a) Composite plate tablets

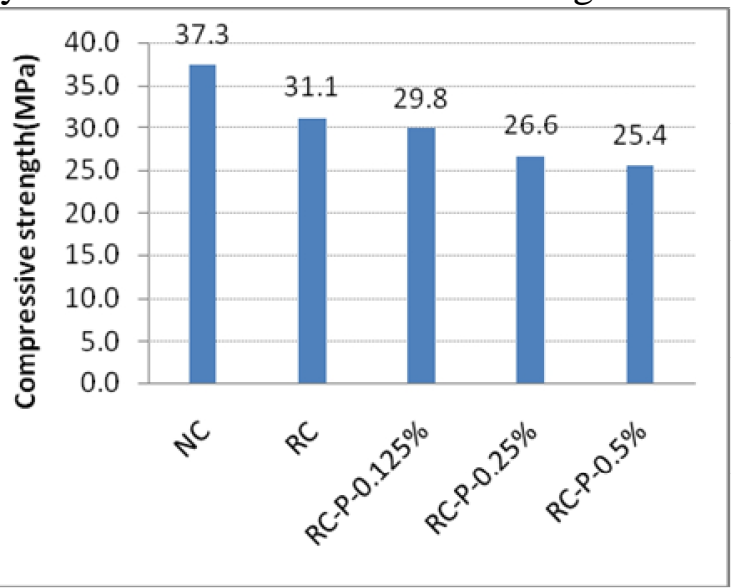

b) PET fibers 


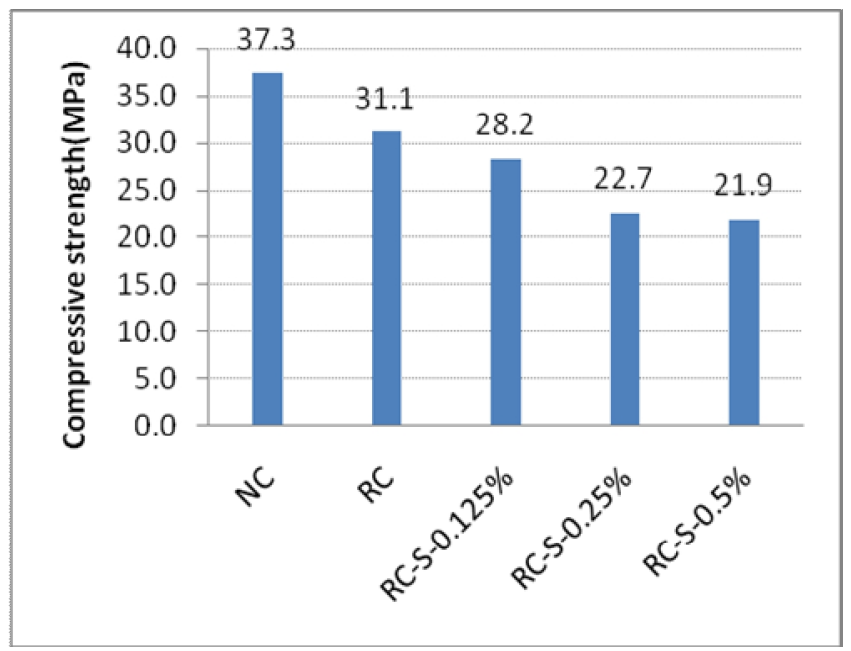

c) Sisal fibers

Fig. 3Compressive strength

Young's modulus. Fig. 4shows the Young's modulus of NC, pure RC and RC in-filled additives. Firstly, it is found that the Young's modulus of RC is only $70 \%$ of NC. Secondly, composite tablets and PET fibers pose slight influence on the Young's modulus. However, the influence of sisal fibers on the Young's modulus is remarkable, which should also result from the air bubbles generated by sisal fibers themselves. The Young's modulus decreases by $16 \%$ as to pure RC when the ratio of sisal fibers is $0.5 \%$.

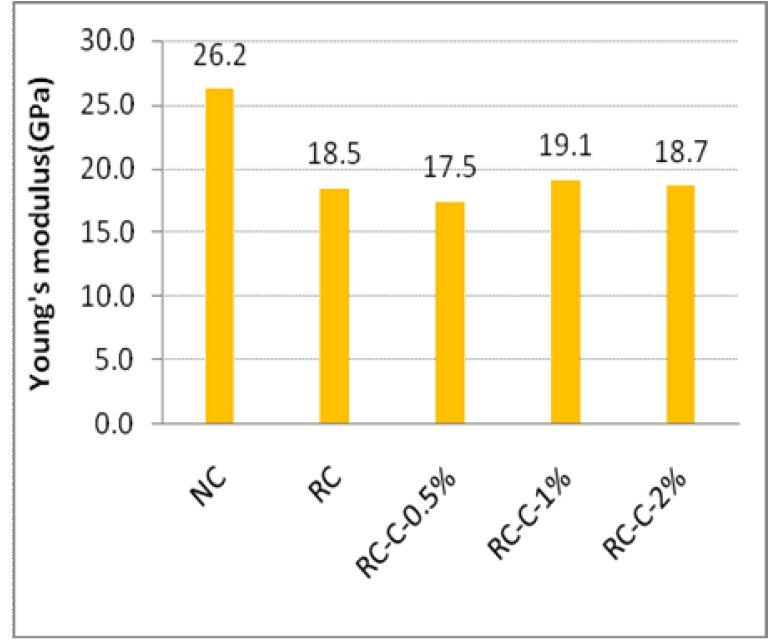

a) Composite plate tablets

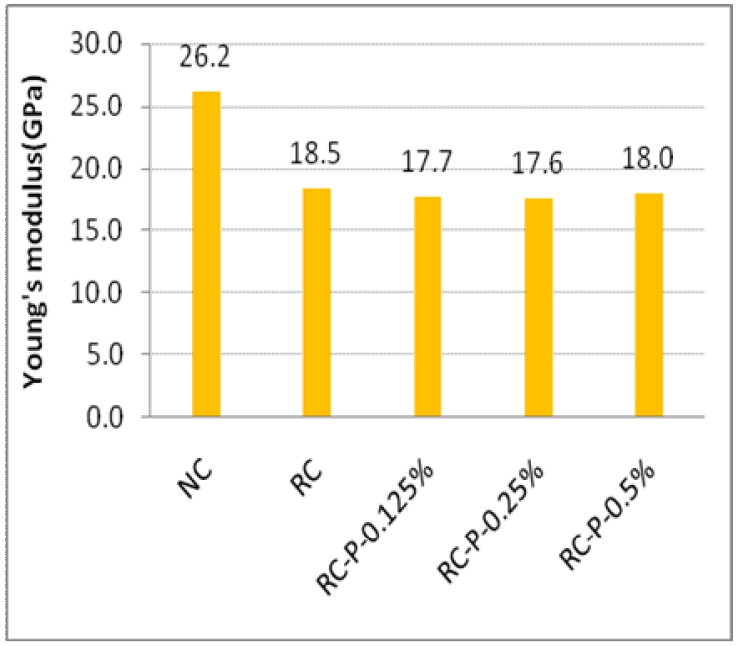

b) PET fibers

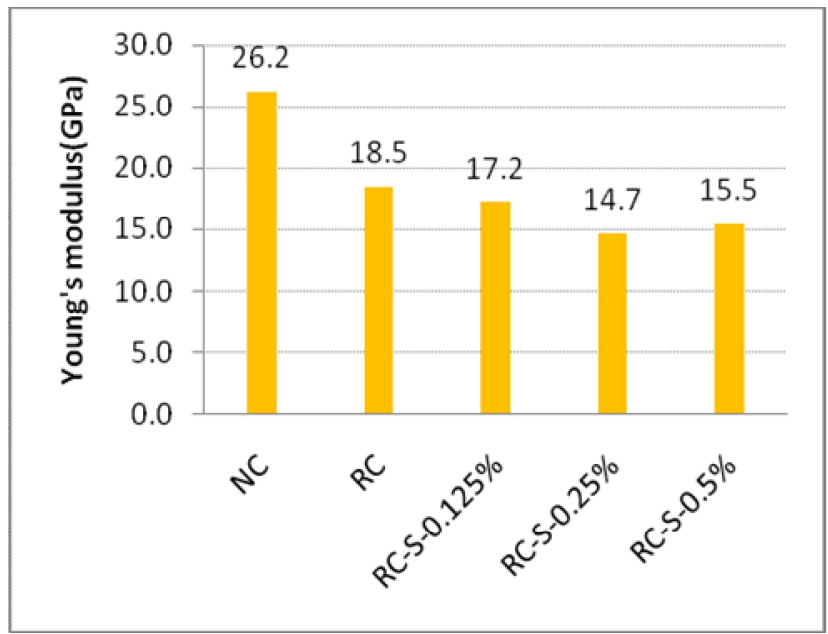

c) Sisal fibers

Fig. 4Young's modulus 


\section{Conclusions}

The glass-fiber composite tablets degrade the compressive strength, which may be result from their smooth surfaces acting as weak points in RC. It does not influence the Young's modulus of RC significantly. Further study can focus on longer composite tablets, which may provide a better bridge effect, and then improve the strength of RC.

PET fibers and sisal fibers can improve the ductility of RC obviously, while, they degrade the compressive strength. The extra water added into PET fibers and sisal fibers may result in dropping down the strength. Further study should focus on the mix procedure to avoid adding extra water.

Sisal fibers can generate small air bubbles, which influence the mechanical properties of cement paste. Further studies should be conducted to reveal the mechanism of air bubbles and develop pretreatments to prevent the generation of air bubbles.

\section{References}

[1] J. Xiao: Recycled concrete (China Architecture and Building Press, China 2008). (In Chinese)

[2] J. Xiao, J. Li and C. Zhang: Mater. Struct., Vol. 39 (2006), p. 655

[3] C.S. Poon and D. Chan: Constr. Build. Mater., Vol. 20 (2006), p. 569

[4] J. Xiao, W. Li, Y. Fan and X. Huang: Constr. Build. Mater., Vol. 31 (2012), p. 364

[5] J. Carneiro, P. Lima, M. Leite and R. Filho: Cement and Concrete Comp., Vol. 46 (2014), p. 65

[6] H. Dilbas, M. Şimşek and Ö. Çakır: Constr. Build. Mater., Vol. 61 (2014), p. 50

[7] Z. Zhao, S. Wang, L. Lu and C. Gong: Constr. Build. Mater., Vol. 43 (2013), p. 191

[8] B. Zhan, C.S. Poon, Q. Liu, S. Kou and C. Shi: Constr. Build. Mater., Vol. 67 (2014), p. 3

[9] V.W.Y. Tam and C.M. Tam: Constr. Build. Mater., Vol. 22 (2008), p. 2068

[10]F. Fraternali, V. Ciancia, R. Chechile, G. Rizzano, L. Feo and L. Incarnato: Compos. Struct., Vol. 93 (2011), p. 2368

[11]F. A. Silva, R. Filho, J. Filho and E. Fairbairn: Constr. Build. Mater., Vol. 24 (2010), p. 777 